\title{
Sequence Number
}

National Cancer Institute

\section{Source}

National Cancer Institute. Sequence Number. NCI Thesaurus. Code C70710.

A number that identifies the ordering relations (in time, space, etc.) in a set of objects or events. 